\title{
Erratum to: Joint subcarrier and power allocation for downlink cellular OFDMA systems by intercell interference limitation
}

Seyed Mehdi Hosseini Andargoli •

Kamal Mohamed-pour

Published online: 31 August 2013

(C) Springer Science+Business Media New York 2013

Erratum to: Telecommun Syst

DOI 10.1007/s11235-013-9693-2

The article was published with an incorrect affiliation for the second author (Kamal Mohamed-pour). The correct affiliation is shown in this erratum.

The online version of the original article can be found under doi:10.1007/s11235-013-9693-2.

S.M. Hosseini Andargoli $(\bowtie)$

Dep. of Electrical Engineering, Babol Noshirvani University

of Technology, Babol, PO Box 47148-71167, Iran

e-mail:smh_andargoli@nit.ac.ir

K. Mohamed-pour

Dep. of Electrical Engineering, K.N. Toosi University of

Technology, PO Box 16315-1355, Tehran, Iran

e-mail:kmpour@kntu.ac.ir 